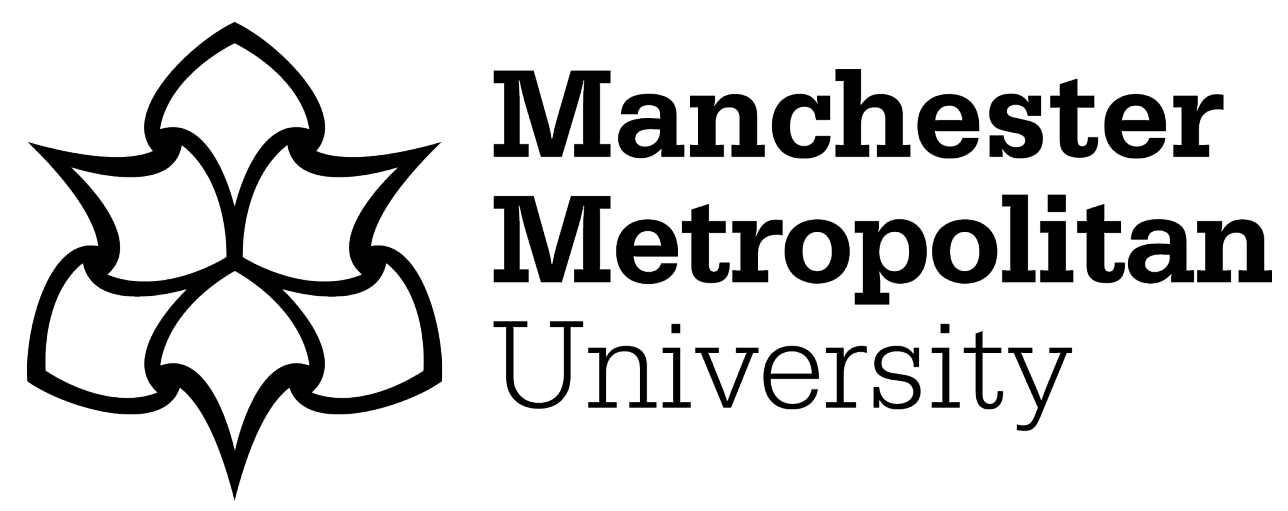

Kayas, Oliver George ORCID logoORCID: https://orcid.org/0000-0003-45418171, Assimakopoulos, Costas and Hines, Tony (2022) Student evaluations of teaching: emerging surveillance and resistance. Studies in Higher Education, 47 (1). pp. 1-12. ISSN 0307-5079

Downloaded from: https://e-space.mmu.ac.uk/624999/

Version: Accepted Version

Publisher: Taylor \& Francis (Routledge)

DOI: https://doi.org/10.1080/03075079.2020.1725875

Please cite the published version 


\title{
Student evaluations of teaching: emerging surveillance and resistance
}

\author{
Abstract \\ Despite previous research claiming surveillance emerges from student evaluations of teaching \\ (SET), there is an absence of research using surveillance theory to determine whether it \\ emerges, the nature of the surveillance should it emerge, and how academics resist its effects. \\ Through an analysis of four university business schools, a top-down vertical surveillance \\ imbued with disciplinary procedures is identified, involving a few managers scrutinising \\ many academics through the observations of many students. A bottom-up vertical \\ surveillance is also identified, involving many academics scrutinising a few managers \\ through the observations of many students. The similarities and differences between mystery \\ shopping and the surveillance emerging from SET are also explored to highlight the crucial \\ role students play in the surveillance. A further contribution is made through an analysis of \\ how academics engage in resistance activities designed to disrupt the flow of performance \\ information between observer and observed.
}

\section{Introduction}

Student evaluations of teaching (SET) have become an established performance management tool for universities to measure and evaluate student satisfaction with teaching (Blackmore 2009; Bedggood and Donovan 2012). The seemingly objective nature of these performance management tools has persuaded universities that SET can provide managers with auditable performance information to assess whether academics achieve teaching expectations (Bedggood and Donovan 2012). SET have several potential benefits: providing management with insight that can be used to validate a new programme; providing management with information about academic performance; providing students with a source of information to aid their choice of where to study (Collini 2012); providing students with a voice to express their satisfaction with teaching; and providing academics with feedback to improve their teaching (Johnson 2000). Despite the potential benefits, it has been suggested that academics experience SET as a form of surveillance.

Workplace surveillance refers to management's ability to observe, record, and track employee performance, behaviour, and personal characteristics (Ball 2010), appealing to moral criteria relating to direction, proscription, and control (Lyon 2006). Existing research suggests that surveillance emerges from SET, yet these studies do not draw on surveillance theory to determine whether it emerges or the nature of the surveillance should it emerge. It 
has been claimed, for example, that SET enact a form of surveillance that creates feelings of anger and fear amongst academics whilst also damaging working relationships (Blackmore 2009; Johnson 2000). Ogbonna and Harris (2004) suggest that management increasingly use SET as a surveillance mechanism that drives 'student-focused' emotional labour. This creates pressures for academics to conform to student feedback, subjugating their identity in a quest for standardisation, thereby, engendering an incompatibility between academics' real emotions and that desired by universities. Webber (2006) claims that SET act as a form of surveillance for how feminist pedagogies are enacted by faculty members. Elsewhere, it has been suggested that surveillance increases the instrumentalisation of working practices to the extent that academic performance is constantly observed and evaluated (Worthington and Hodgson 2005; Craig, Amernic, and Tourish 2014). There have even been suggestions that academics now work in a context of normalised surveillance that constantly marks them as successes or failures (Lorenz 2012; Craig, Amernic, and Tourish 2014).

Furthermore, while previous research examines academic resistance to SET, there is an absence of research exploring the academic response to the surveillance emerging from SET. This paper therefore analyses SET through the rubric of surveillance to offer new insight into the effect surveillance has on levels of control and trust, staff relations, and the way in which surveillance influences social change through the working practices embedded in institutional practices (Ball 2010). The aim of the paper is to identify and examine whether surveillance emerges from SET, the nature of the surveillance should it emerge, and how academics resist its effects. The paper begins with a discussion of surveillance and resistance. The methodology section outlines the rationale for a qualitative analysis of four university business schools. The findings are then presented and discussed. The paper concludes by summarising the implications of the research, its limitations, and future research opportunities.

\section{Surveillance}

Employees often expect managers to use performance management tools to have their performance reviewed, objectives set, and activities monitored and measured (Ball 2010; Marx 1999). Employees may even perceive performance management as a legitimate and impartial tool serving the interests of everyone in the organisation if it informs decisions around rewards and promotions whilst also exposing antisocial issues like free-riding or favouritism (Sewell, Barker, and Nyberg 2011). Not all performance management systems give rise to surveillance. However, surveillance emerges from performance management 
systems when managers in positions of authority do not trust employees to achieve performance expectations (Marx 1999; Sewell 2012; Zureike 2003). Unlike performance management, surveillance more narrowly refers to an intrusive and oppressive practice imposed on employees by managers to serve a narrow set of organisational interests concerned with intensifying work and reducing autonomy (Sewell, Barker, and Nyberg 2011). Such distrust encourages management to use information technologies that automatically generate the performance information needed to deconstruct employees so they can be constantly scrutinised and controlled (Zureike 2003). This intensifies the collection of performance information and negatively compromises levels of control, autonomy, and trust (Ball 2010). The principal purpose of surveillance is not to protect against antisocial behaviour, but to ensure that employees constantly work as hard as they possibly can (Ball 2010; Marx 1999; Sewell, Barker, and Nyberg 2011). This increases the feeling that organisations measure everything that moves and raises socio-theoretical concerns about the dystopian characteristics of power, politics, and resistance (Ball 2010; Sewell, Barker, and Nyberg 2011; Marx 1999).

According to Sewell, Barker, and Nyberg (2011), surveillance enables managers to identify those employees who fail to 'measure up' to organisational expectations and values. Managers use surveillance to categorise individual employees as either satisfactory or unsatisfactory performers and to determine whether their status is 'deviant', 'normal' or 'useful'. They observe that when surveillance is rendered, managers believe they are asserting their right to scrutinise employees to ensure that organisational expectations are achieved. Employees therefore find themselves subjected to a managerial gaze that constantly tracks and records their performance (Ball 2010). Under these circumstances, however, employees may fight a 'battle to assert their autonomy against this unwelcome intrusion' such that they derive experiences of surveillance as a form of excessive performance management (Sewell, Barker, and Nyberg 2011).

Central to the notion of surveillance is that employees subjected to it will enact the behaviours of those watching them whilst conforming to the organisational values embedded within the gaze (Iedema and Rhodes 2010). This draws upon the principles of the panopticon conceived by Jeremy Bentham and later extended by Michel Foucault (1977). The panopticon is premised on the principle that a few managers observe many employees who know they could be observed at any given time but do not know the precise moment they are being observed. These observations are coupled with disciplinary punishments, forcing employees to assume responsibility for their behaviour by internalising the gaze through a 
power relation in which they are the principle of their own subjection. This renders management superfluous and establishes a disciplinary form of surveillance maintained by employees through an asymmetrical power relation.

Despite its influence on the field of surveillance, the panopticon has been criticised for excluding aspects of surveillance that fall outside of its framework (Lyon 2006). Vertical surveillance is embedded within hierarchical power relations concerned with comparing individual performance against organisational expectations (Sewell 2012, 1998). It involves a supervisor in a position of authority using information technologies to classify the performance of subordinates as 'good' or 'bad' (Sewell 2012). While this top-down form of vertical surveillance is most common, there is also a bottom-up form of vertical surveillance, involving subordinates observing managers (Sewell 2012). Another form of surveillance involves inspectors enrolling others to observe employees on their behalf. This occurs when employees find themselves subjected to the scrutiny of mystery shoppers who are employed by managers to measure customer satisfaction (Domenico and Ball 2010; Wilson 1998). The surveillance emerging from mystery shopping is covert if employees are not informed that they are observed by mystery shoppers. If employees are told they are observed then it is overt, but it is simultaneously covert as employees do not know who a genuine customer is.

\section{Resistance}

Despite management's attempts to engender surveillance, there are always blind spots where individuals can resist its effects (Sewell 1998). According to Ball (2010), studies examining resistance to surveillance tend to draw upon labour theory arguments about the oppressive nature of control as well as Foucauldian arguments about the totalising desire of institutions to outflank resistance. Sewell's (1998) examination of labour theory highlights how the control of work is the principal mechanism by which labour is subordinated by management. He identifies scientific management (Taylorism) as the most significant innovation in the pursuit of labour control, as it not only seeks to identify the best way to work, but also how best to control labour that might resist management. Sewell also examines Foucault's contribution to labour theory by revealing how the panopticon is used by management to capture knowledge of employee performance under a totalising instrumental rationalism that marginalises dissent and resistance. In this context, resistance is conceptualised as a struggle against the labour process to prevent or minimise managerial encroachments by challenging or disrupting their assumptions, discourses, and power relations in increasingly pervasive organisational contexts (Mumby, Thomas, and Martí 2017). It manifests when employees 
assert their autonomy through individual and collective behaviours because they are dissatisfied with the intensification of their jobs and the detrimental effect it has on their wellbeing.

Previous research examining academic resistance to SET draws upon these labour theory arguments of control. Siguaw and Simpson (2000) observe how academics perceive SET as problematic and therefore attempt to overcome them by lowering standards to appease students. They also show how academics introduce inducements to influence student ratings. Iqbal (2013) found that SET rarely fulfil their objectives because of a lack of engagement in the process by academics. Martin (1998) reveals how academics game student ratings in their favour by using practices that distract from learning rather than enhancing learning. Risquez, Vaughan, and Murphy (2015) found that while many academics appreciated the efficiency of online SET over paper-based SET, the lower student response rates experienced with the online system created a level of non-engagement by academics. Elsewhere, Wentworth, Behson, and Kelley's (2018) examination of the implementation of a new SET highlights how some academics resisted change efforts by delaying communications.

While extant research examines resistance to SET using traditional labour theory arguments, there is an absence of research analysing resistance to the surveillance emerging from SET. According to Ball (2010), when examined through the rubric of surveillance, resistance occurs when there is a break in the technology-mediated relationship between the observer and the observed. This involves employees circumventing surveillance by resisting the extraction of information to elude control. Breaking the flow of information enables employees to silence themselves by not giving out the valuable information management need to exercise control. Marx (2003) claims that surveillance can also be resisted through distorting moves, which involves employees manipulating the collection of performance information such that technically valid results are offered, but invalid inferences are drawn. He also highlights how employees can resist surveillance by preventing the extraction of performance information by refusing to do what is expected of them. This may involve an employee ignoring an authority or 'just saying no' to their request.

\section{Context}

Performance management became a concern for UK universities with the widespread adoption of New Public Management and, in particular, with the changes proposed by the Jarratt Committee in 1985 (Franco-Santos, Rivera, and Bourne 2014). In line with the New Public Management movement, the committee proposed that universities redirect their 
strategies to focus on performance management practices, emphasising quantitative performance indicators, the accountability of results, and staff appraisals. Alongside these changes, external organisations were introduced to evaluate teaching quality in higher education institutions. The Quality Assurance Agency was formed in 1997 to conduct quality assessment reviews to determine whether universities maintain academic standards. In 2017 the Teaching Excellence Framework was introduced to provide standardised measures of teaching quality. This was followed by the Office for Students in 2018, which holds universities accountable for teaching quality. While these changes do not require universities to implement SET, many have developed SET to measure student satisfaction with teaching.

\section{Method}

A qualitative analysis of four UK university business schools was undertaken to elucidate the surveillance emerging from the performance management practices embedded in SET.

Recruitment targeted a heterogeneous sample of academics working at universities in the UK. Four universities agreed to participate in the study. Two of the universities are classified as a post-1992 (new) universities and the other two are classified as a pre-1992 (old) universities. The universities and participants in this study are given anonymity to protect their identity. The two new universities are referred to as University Alpha and University Beta. The two old universities are referred to as University Omicron and University Omega.

The research utilised semi-structured interviews (Rubin and Rubin 2012) and document analysis. The documents included: annual reports, customer service strategies, disciplinary procedures, education strategies, human resource policies, IT strategies, student evaluation strategies, and performance management reports. These public documents were analysed prior to the interviews to provide insight into the context of the four universities.

A total of 34 interviews were conducted. There were 19 female participants and 15 male participants aged between 26 and 68 with a range of teaching and research experiences. Participants included managers: heads of department, deputy heads of department, and principal lecturers (new universities only). Participants also included academics: professors, senior lecturers, and lecturers. To be included in the study, participants had to have worked at their current university for at least one academic year.

An interview protocol was designed around the different perspectives presented in the literature to ensure that the researchers did not drive an agenda that sought to show that surveillance emerges from SET (Gibbs 2007). Designing the interview protocol in this way allowed for a detailed exploration of the different views on SET: the claim that they can 
engender teaching benefits as well as the claim that they render surveillance. Participants worked in different academic departments to yield multiple perspectives. Eleven interviews were undertaken at University Alpha; eight at University Beta; seven at University Omicron; and eight at University Omega. Interviews took place in rooms on campus and were recorded for analysis. Participants were briefed about ethical considerations and invited to ask questions before the interviews started. Each interview lasted approximately one hour. Interview comments were restated and discussed to enhance credibility through respondent validation (Creswell 2013). Participants were invited to add any additional comments at the end of each interview.

The interviews were analysed using thematic analysis to identify and interpret patterns in the data (Braun and Clarke 2006). The analysis involved the researchers analysing the data during the data collection process to identify interesting areas to pursue as they emerged (Gibbs 2007). This served as a member checking, confirmation and revision mechanism through which construct validity was established, supporting and illuminating the interpretation of the data (Creswell 2013). Each researcher independently analysed the data to become familiar with it (Braun and Clarke 2006). The researchers then discussed their findings to identify themes and to ensure one researcher did not dominate the theoretical horizon (Gibbs 2007). The interview data were related to the literature to enhance the reliability of the analysis, enabling the researchers to build valid arguments for choosing themes (Creswell 2013). Relevant data were collated into themes and they were then defined and named. This iterative process enabled the identification of nuanced themes that were corroborated or adjusted to add depth and texture to the analysis. Two themes emerged from the analysis: surveillance and resistance.

\section{Findings and discussion}

\section{Surveillance}

The value all four universities place on student opinion is enshrined in their internal documentation: 'Listening to the student voice is a priority for us. The student survey helps us to improve the academic experience for current and future students by giving them an opportunity to share their opinions, so that any necessary improvements can be made' (Corporate Strategy, University Omicron). Similarly, the Customer Service Strategy at University Beta states: 'Students are crucial as they provide valuable feedback enabling us to maintain and improve the quality of our teaching services. Evaluating student opinion and responding to their views is a key indicator for the assurance and enhancement of service 
quality.' All four of the business schools evaluate student opinion through SET made available to students through online surveys at fixed points throughout the academic year. Academics are emailed telling them to promote student participation in SET and students are encouraged to complete SET through emails sent to their university account. The SET ask students to assess each module and programme using a Likert scale. The questions vary between the four business schools, but common questions include: How satisfied are you with this module? How satisfied are you with the teaching on this module? How satisfied are you with the online resources for this module? How satisfied are you with the availability of your tutor? How satisfied are you with the programme? The SET also allow students to write qualitative comments. The results are made available through a spreadsheet or dashboard, showing student response rates and satisfaction scores for each question.

Information technologies provide a crucial element of the infrastructure underpinning SET, as they automatically transform student feedback into performance information that reduces each academic to a Likert score. This engenders a disembodied gaze that frees managers from the architecture of the workplace by enabling them to scrutinise and control each academic without a direct line of sight into the classroom (Sewell 2012; Zureike 2003). This reductionist approach to performance management dehumanises academics by defining them as performance instruments judged by performance results alone. Standardising performance information in this way has seen performance targets embedded in teaching practices throughout the four business schools. Employment contracts do not specify the performance targets academics must achieve. However, they are enshrined in publicly available university documents: 'We need to know if our services meet customer expectations. We will actively collect customer feedback and use it to improve our services. We aim to achieve student satisfaction scores of mean 4.0 and above' (Student Evaluation Strategy, University Omega). Managers throughout the four business schools outlined the strict performance targets academics are expected to achieve:

I can see the score and compare each module during the different terms to see how they're progressing throughout the year. If there are any low scoring modules, I can see which I need to focus on... We aim for a 6 [out of 7 which is a university determined target], but if a module scores less than five and a half then I'll need to look at it and take remedial action. That's when I'll talk to the module leader to discuss the content and how it's delivered. (Head of Department, University Omicron) 
Modules are expected to hit 4 out of 5, but I tell staff to aim high with 4.2. If it's below 3.6 I'll have a chat with the teaching team... I aim high because I don't want to be called to a meeting with the Dean to explain why we underperformed. (Principal Lecturer, University Beta)

The comments above indicate that SET are not only dependent on information technologies that automatically collate performance information, they also involve a social process that depends on managers intervening where necessary to regulate and control academic behaviour. Managers believe the ability to evaluate and control academics in this way is important to ensure university expectations are achieved (Blackmore 2009; Bedggood and Donovan 2012). However, academics across the four business schools expressed a sense of frustration about the performance targets to the extent that they perceive them as a form of excessive performance management:

You're always worried about the feedback because if you get less than 4 out of 5, you're not compliant... I got 3.5 on an undergraduate module, so I got an email from [the deputy head of department] inviting me to a meeting to discuss my performance. It was really stressful. (Senior Lecturer, University Alpha)

I was on the naughty step because my module got 3.9 when [management's] expecting 4 out of 5. The targets are absurd. Why should I be accountable to students when some of them haven't even attended half the lectures? (Lecturer, University Omega)

These findings reveal that while these performance targets are designed to ensure teaching expectations are achieved, academics resent the intensification of performance management as it extends management control, increases levels of stress, and negatively affect levels of trust:

It's not a collegiate environment where they trust you to develop your teaching. Why else would management monitor everything that you do? (Professor, University Omega)

The student survey has really intensified in recent years... It's a really stressful environment... It doesn't feel like management trust me to do what I'm paid to do. (Senior Lecturer, University Omicron). 
Despite resenting the intensification of performance management, a benefit of using SET was outlined by a Lecturer at University Omega: 'The [student] survey means I don't need to bother seeing the Programme Leader to discuss how things can be improved: I can see for myself on the dashboard'. Such responses were extremely limited across the four business schools. For most academics, the benefits of SET are outweighed by the view that they increase feelings of mistrust and extend management control. Academics are justified in their claim that management do not trust them to achieve teaching expectations, as many managers confirmed the distrust they have for academics:

I use the performance information from the [student $]$ survey to check whether staff are performing as expected. Without the feedback we've got no way of measuring whether staff are doing what they're supposed to... I use [the performance] information to keep things in check and, if necessary, I'll take corrective action. (Head of Department, University Omega)

We can't just let [academics] get on with teaching without knowing what they're doing or how it's going. That's why we need the student survey. (Principal Lecturer, University Beta)

These findings support the claim that surveillance emerges from performance management systems because employees are not trusted to achieve performance expectations (Marx 1999; Sewell 2012; Zureike 2003; Ball 2010). This lack of trust and the strict performance targets result in academics being subjected to the constant gaze of students as well as the ever-watchful gaze of management:

It's like having a food critic in your restaurant every single day judging you on every single meal you ever make... The [IT] system automatically produces reports for management so there's no escape. You're constantly judged by students and management. (Senior Lecturer, University Beta)

We get feedback from hundreds of students on the larger modules... Being monitored by so many students and then being checked by management creates an unbelievable amount 
of pressure. Some people can take it on the chin, but for many people, myself included, it gives you sleepless nights. (Lecturer, University Alpha).

I've got students evaluating me during every single lecture and during every single seminar. Then I get it from my head of department at the end of every term. It never ends... You feel like you're slowly being suffocated. (Senior Lecturer, University Omega)

It's management who want to get into the classroom with us and judge our teaching. The observations students make and then feedback through the student survey are gospel because [management] use it to keep an eye on your performance. (Senior Lecturer, University Beta)

Management's observations are rooted in what academics perceive as excessive performance management infused with feelings of mistrust, engendering a form of top-down vertical surveillance embedded in the hierarchical power relations in the four business schools (Sewell 2012; Ball 2010). It involves managers using the performance information derived from SET to pervade the working lives of academics to measure and categorise them into distinct categories: those who achieve performance expectations and those who do not. Managers believe this top-down vertical scrutiny is necessary, as it supports their right to constantly extract maximum effort from academics by forcing them to comply with management-imposed performance expectations (Sewell, Barker, and Nyberg 2011). This intrusive form of surveillance is imposed on academics and serves a narrow set of managerial interests concerned with intensifying work and reducing autonomy. The surveillance therefore perpetuates management's position in formal hierarchical power structures with little such benefit conferred on academics.

Alongside this top-down vertical surveillance, the findings also reveal a form of bottomup vertical surveillance. This involves academics inverting the gaze and using the performance information derived from SET to observe and evaluate how managers perform. This reverses formal hierarchical power structures, allowing subordinates to hold managers to the same performance standards imposed on them whilst also enabling them to scrutinise and categorise managers as either satisfactory or unsatisfactory:

Last year there were a few complaints about the lecture theatre. The room wasn't conducive to a lecture for the numbers, and the students made that very clear on the 
[student] survey... Room bookings are down to management, so I had a meeting with [my deputy head of department] about the feedback. I made it clear that she needed to address the problem... I had to chase her up about it a few weeks later because she hadn't done anything about it. (Lecturer, University Alpha)

These two forms of vertical surveillance (top-down and bottom-up) involve managers and academics evaluating each other's performance to ensure conformance with university expectations (Sewell 1998). However, the vertical surveillance emerging from SET goes beyond extant notions of managers and employees observing and evaluating each other, as students also play a crucial role in the vertical surveillance. The top-down surveillance in the four business schools involves a few managers scrutinising many academics through the observations of many students, whilst the bottom-up surveillance involves many academics scrutinising a few managers through the observations of many students. This has implications for students as they are transformed into surveillance instruments that have no formal power, but nevertheless form a crucial component in the surveillance, as it collapses without their participation. This differs significantly from extant notions of vertical surveillance, as it is dependent on others generating the required performance information.

The role students play in this surveillance is further highlighted when analysed within the context of mystery shopping. Like mystery shoppers, students are enrolled by universities to provide feedback on academic performance. However, the findings reveal three differences between the surveillance emerging from mystery shopping and the surveillance emerging from SET. First, students are not employed or paid by managers to observe and evaluate academics. Instead, universities encourage student participation by framing it as strengthening and empowering the student voice. Second, while mystery shoppers evaluate some employee interactions (Wilson 1998), students can observe academics during every single class throughout the entire academic year. This creates a pervasive gaze that constantly scrutinises academics whilst fuelling feelings of mistrust between academics, managers, and students. Finally, while mystery shoppers undertake covert observations and make every effort to mask their role (Domenico and Ball 2010; Ball 2010), there is no deception with students observing academic performance: academics know students are observing and evaluating their performance. Students also know that academics are aware of them observing and evaluating their performance. This creates an overt gaze as academics know they are observed by students and then scrutinised by the 'all-embracing' surveillant gaze of 
management (Domenico and Ball 2010). However, the gaze is also covert, as academics do not know which students will participate in the evaluation of their performance.

SET have significant implications for academic identities. Academics in all four business schools outlined how the surveillance enables students to influence the design of teaching: 'Students don't like exams, so they don't do exams. Students don't like the delivery method, so it gets changed. Student satisfaction comes first so we have to do what they want to keep them happy' (Senior Lecturer, University Alpha). The knowledge and expertise of professional educators is therefore compromised, as student opinion is given primacy when developing teaching. This reinforces the Foucauldian view that surveillance reengineers the professional identity of academics to ensure they conform to university standards determined by those in positions of power (Worthington and Hodgson 2005). It also supports the claim that management use SET to drive student-focused emotional labour, putting academics under pressure to conform to student feedback whilst subjugating their professional identity in a quest for standardisation (Ogbonna and Harris 2004). This adds to the claim that academics work in a context of normalised surveillance (Lorenz 2012; Craig, Amernic, and Tourish 2014), and highlights the ongoing sense of mistrust that management have for academics in their role as professional educators.

The multidirectional and multilayered surveillance emerging from SET is intensified because academics are subjected to disciplinary punishments for failing to achieve performance expectations. Disciplinary procedures are outlined in human resource policies to ensure processes are in place to identify and correct academics who fail to achieve performance expectations. Managers and academics outlined their severity:

There's someone in the department who's scored low on the [student] survey for a few years. She's got to be careful because this year she's going through an official performance review and, if she doesn't do well, she's going to be performance managed out. (Principal Lecturer, University Alpha)

A colleague of mine has scored low on several modules and he's been identified as a weak link in the chain. He's got to be careful because he might find himself out of here. (Lecturer, University Omega) 
[A colleague] recently lost her job because her new head of department didn't think she was performing... The worrying thing is that [the head of department's] decision was informed by the student survey. (Senior Lecturer, University Beta)

These disciplinary punishments are embedded in the gaze to ensure academics conform to university expectations. The threat of punishment embeds a power relation in the gaze designed to control the performance of academics. This forms part of the organisational compulsion to rationalise and control individuals to fully integrate them into university life (Sewell 2012). The surveillance emerging from SET therefore confers massive benefits on the employer, but relatively little benefit on academics, as there are no formal procedures to reward them for exceeding performance expectations. The findings also differ from previous studies claiming that research informs decisions around retention and promotion (Cadez, Dimovski, and Groff 2017), by revealing that teaching also influences decisions around retention but not promotion.

Academics also revealed that if they are identified as underperformers, they receive little to no support or training:

Training? What training? It's bullshit. The so-called training covers things like diversity, data protection, and the admin side of teaching, but not the practicalities of delivering a seminar... We have peer observations, but you might get paired with someone who gets weak or average feedback... There's no one to support you with teaching, but there'll always be someone to tell you that you're not on target. (Lecturer, University Alpha).

This lack of support heightens academic feelings of performance anxiety and exacerbates feelings of mistrust towards management. These findings also contradict university policies outlining the importance of 'investing in staff development so they have the skills and knowledge to excel in their jobs' (Organisational Strategy, University Alpha) as well as claims that universities are 'providing continuing professional development opportunities for professional colleagues involved in supporting the student learning experience' (Staff Development Report, University Omega). This suggests that while universities describe staff development as an important university value to support the student learning experience, the performance information derived from SET is used primarily to identify and discipline underperforming academics. This has implications for students, as academics are not provided with development opportunities to enhance the student learning experience. 


\section{Resistance}

Despite the surveillance emerging from SET, there are academics who resist its effects. Academics play a crucial role in the production of the performance information underpinning the surveillance, as management require them to promote SET to students. The sample size managers use to observe and evaluate academic performance is therefore influenced by academics participating in the promotion of SET. Academics recognise the value the performance information underpinning the surveillance has to management, and that disrupting its production will enable them to evade management control. As a result, academics often refuse to promote SET to reduce the reliability of the sample size. This creates a gap in the surveillance and limits management's ability to determine whether academics need subjecting to disciplinary procedures:

We get bombarded by emails from management telling us to push the student survey, but I never do. Last year just one student completed the [student] survey for a postgraduate module I run... Management left me alone because they couldn't gauge what was going on from just one response. (Senior Lecturer, University Alpha)

I never tell students to complete the [student] survey because it's more trouble than it's worth... You're just adding fuel to the fire. The more students who complete the survey the more headaches you'll get... The less [performance] data management get the better. (Senior Lecturer, University Omicron)

I don't bother promoting the [student $]$ survey because it gives management access to [performance] information that they might end up using against you. The last thing I need is a meeting with [my head of department] because I haven't hit my targets. (Lecturer, University Beta)

Other academics resist the surveillance through distorting moves. These distorting moves reveal how academics consider the student response to SET and attempt to manipulate the outcome of the surveillance by introducing bias into student opinion. While these acts of resistance still yield technically valid results, managers draw invalid inferences from their observations thereby reducing the chances of academics being subjected to disciplinary punishments (Marx 2003): 
It's simple: if student don't do well on their assignment, they'll just score you down on the student survey. Then management will be on your back and you could end up in their office having an uncomfortable conversation. So, where's the motivation for me to sell the $[$ student $]$ survey? (Professor, University Beta)

I never give [assessment] results when the student survey is available because they'll only mark you down if they're not happy with their mark. (Senior Lecturer, University Alpha)

I don't give students additional work or reading when they're asked to complete the [student] survey. It'll just lower my module's score. (Lecturer, University Omicron)

The first two comments show how some academics do not return assessment grades to students at the same time SET are made available. These academics believe that if students score poorly on their assessment, they will score the module down and that they could then end up being subjected to disciplinary procedures. Unlike the leniency hypothesis, which posits that academics can ‘buy' higher SET results by awarding higher grades (Marsh 1984), in the four business schools, academics are more concerned with poor performing students who could score their module low rather than strong performing students who could score it high. The third comment shows how some academics carefully time when they increase the student workload because they are concerned with students scoring their module down should they believe they have too much work (Marsh 1984). The wider organisational effect of this resistance is that it encourages academics to focus on a narrow range of measurable performance outcomes to minimise contentious readings. It also favours style over substance to produce thin pedagogies which undermine student learning (Blackmore 2009).

These findings reveal that although surveillance is supposed to make such acts of resistance futile (Sewell 1998), academics can resist its effects to evade its rationalising nature. However, despite these acts of resistance, management expressed no intention of changing how they use SET, as they believe they are asserting their right to scrutinise academic performance (Sewell, Barker, and Nyberg 2011). These acts of resistance have therefore done little to alter university regimes, as management continue using SET to perpetuate power relations to their benefit whilst disproportionately applying them to academics further down the hierarchy. 


\section{Conclusions}

Although previous research suggests surveillance emerges from SET, the debate is here extended by drawing on surveillance theory to identify and elucidate the nature of the surveillance emerging from SET as well as the academic response to the surveillance. A topdown vertical surveillance imbued with disciplinary procedures is identified, involving a few managers scrutinising many academics through the observations of many students. A bottomup vertical surveillance is also identified, involving many academics scrutinising a few managers through the observations of many students. The similarities and differences between mystery shopping and the surveillance emerging from SET were also examined to reveal the essential role students play in the surveillance. Finally, although previous research draws upon labour theory to examine academic resistance to SET, new insights are offered into the resistance strategies academics employ to disrupt the flow of performance information between observer and observed.

With university managers continuing to use SET to collect performance information, there is a need for clarity in terms of what is being measured and how it is being measured. Future research could therefore examine what performance information should be collected and how it should be analysed to reduce surveillance, enhance performance management, and improve levels of trust. However, such research should tread carefully. Producing more performance information could have the opposite effect and further intensify surveillance by extending management's gaze (Ball 2010). Finally, while this research offers insight into SET in four business schools, it cannot claim whether the emerging surveillance is unique to business schools or whether it also occurs in different faculties. Future research could therefore examine whether surveillance emerges from SET in different faculties, the conditions giving rise to it, and whether it differs from that in business schools.

\section{References}

Ball, Kirstie. 2010. "Workplace surveillance: an overview." Labor History 51 (1):87-106. Bedggood, Rowan E, and Jerome D Donovan. 2012. "University performance evaluations: what are we really measuring?" Studies in Higher Education 37 (7):825-42.

Blackmore, Jill. 2009. "Academic pedagogies, quality logics and performative universities: evaluating teaching and what students want." Studies in Higher Education 34 (8):857-72.

Braun, Virginia, and Victoria Clarke. 2006. "Using thematic analysis in psychology." Qualitative Research in Psychology 3 (2):77-101. 
Cadez, Simon, Vlado Dimovski, and Maja Zaman Groff. 2017. "Research, teaching and performance evaluation in academia: the salience of quality." Studies in Higher Education 42 (8):1455-73.

Collini, Stefan. 2012. What are Universities For? London: Penguin Books.

Craig, Russell, Joel Amernic, and Dennis Tourish. 2014. "Perverse Audit Culture and Accountability of the Modern Public University." Financial Accountability and Management 30 (1):1-24.

Creswell, John W. 2013. Qualitative Inquiry and Research Design: Choosing Among Five Approaches. 3 ed. London: Sage Publications Ltd.

Domenico, MariaLaura Di, and Kirstie S Ball. 2010. "A hotel inspector calls: exploring surveillance at the home-work interface." Organization 18 (5):615-36.

Foucault, Michel. 1977. Discipline and Punish: The Birth of the Prison. London: Penguin Books Ltd.

Franco-Santos, Monica, Pilar Rivera, and Mike Bourne. 2014. Performance Management in UK Higher Education Institutions: The need for a hybrid approach. UK.

Gibbs, Graham R. 2007. Analyzing Qualitative Data. London: Sage Publications Ltd. Iedema, Rick, and Carl Rhodes. 2010. "The Undecided Space of Ethics in Organizational Surveillance." Organization Studies 31 (2):199-217.

Iqbal, Isabeau. 2013. "Academics' resistance to summative peer review of teaching: questionable rewards and the importance of student evaluations." Teaching In Higher Education 18 (5):557-69.

Johnson, Rachel. 2000. "The Authority of the Student Evaluation Questionnaire." Teaching In Higher Education 5 (4):419-34.

Lorenz, Chris. 2012. "If You're So Smart, Why Are You under Surveillance? Universities, Neoliberalism, and New Public Management." Critical Inquiry 38 (3):599-629.

Lyon, David. 2006. "The search for surveillance theories." In Theorizing Surveillance: The panopticon and beyond, edited by David Lyon, 3-20. Devon: Willan Publishing.

Marsh, Herbert W. 1984. "Students' Evaluations of University Teaching: Dimensionality, Reliability, Validity, Potential Biases, and Utility." Journal of Educational Psychology 76 (5):707-54.

Martin, J R. 1998. "Evaluating faculty based on student opinions: problems, implications and recommendations from Deming's theory of management perspective." Issues in Accounting Education 13 (4):1079-94. 
Marx, Gary T. 1999. "Measuring Everything That Moves: The New Surveillance at Work " In Deviance in the Workplace, edited by I H Simpson and R L Simpson, 165-90. Bingley: Emerald Group Publishing Limited.

—. 2003. "A Tack in the Shoe: Neutralizing and Resistingthe New Surveillance." Journal of Social Issues 59 (2):369-90.

Mumby, Dennis K, Robyn Thomas, and Ignasi Martí. 2017. "Resistance Redux." Organization Studies 38 (9):1157-83.

Ogbonna, Emmanuel, and Lloyd C Harris. 2004. "Work Intensification and Emotional Labour Among UK University Lecturers: An Exploratory Study." Organization Studies 25 (7):1185-203.

Risquez, Anglica, Elaine Vaughan, and Maura Murphy. 2015. "Online student evaluations of teaching: what are we sacrificing for the affordances of technology?" Assessment \& Evaluation in Higher Education 40 (1):120-34.

Rubin, Herbert J, and Irene S Rubin. 2012. Qualitative Interviewing: The art of hearing data. 3 ed. London: Sage Publications Ltd.

Sewell, Graham. 1998. "The Discipline of Teams: The Control of Team-based Industrial Work through Electronic and Peer Surveillance." Admtnistrattve Science Quarterly 43 (2):397-428.

_. 2012. "Organization, employees and surveillance." In Routledge Handbook of Surveillance Studies, edited by Kirstie Ball, Kevin Haggerty and David Lyon, 303-12. Oxon: Routledge.

Sewell, Graham, James R Barker, and Daniel Nyberg. 2011. "Working under intensive surveillance: When does 'measuring everything that moves' become intolerable?" Human Relations 65 (2):189-215.

Siguaw, Judy A, and Penny M Simpson. 2000. "Student Evaluations of Teaching: An Exploratory Study of the Faculty Response." Journal of Marketing Education 22 (3):199-213.

Webber, Michelle. 2006. "Transgressive pedagogies? Exploring the difficult realities of enacting feminist pedagogies in undergraduate classrooms in a Canadian university." Studies in Higher Education 31 (4):453-67.

Wentworth, Diane Keyser, Scott J Behson, and Catherine L Kelley. 2018. "Implementing a new student evaluation of teaching system using the Kotter change model." Studies in Higher Education. doi: 10.1080/03075079.2018.1544234. 
Wilson, Alan M. 1998. "The Use of Mystery Shopping in the Measurement of Service Delivery." Service Industries Journal 18 (3):148-63.

Worthington, Frank, and Julia Hodgson. 2005. "Academic labour and the politics of quality in higher education: a critical evaluation of the conditions of possibility of resistance." Critical Quarterly 47 (1-2):96-110.

Zureike, Elia. 2003. "Theorizing surveillance: The case of the workplace." In Surveillance as Social Sorting: Privacy, risk and digital discrimination, edited by David Lyon, 31-56. London: Routledge. 